\title{
Techno-economic analysis of solar PV power-to-heat-to-power storage and trigeneration in the residential sector
}

\author{
A. Datas \\ , A. Ramos \\ C. del Cañizo
}

- Techno-economic assessment of residential power-to-heat-to-power storage.

- The integration with a solar PV system in a dwelling in Madrid is considered.

- Electricity savings beyond $70 \%$ and payback periods lower than 15 years are possible.

- Payback periods lower than 10 years are possible when using an absorption chiller.

- Additional fuel savings of $20 \%$ are possible due to the consumption of exhaust heat.

Keywords:

PHPS

CCHP

TES

Trigeneration

Cogeneration

Energy storage

Heat

Thermal

Photovoltaics

Solar

Self-consumption

Thermophotovoltaics

Stirling

Ultra-high temperature

\begin{abstract}
A B S T R A C T
This article assesses whether it is profitable to store solar PV electricity in the form of heat and convert it back to electricity on demand. The impact of a number of technical and economic parameters on the profitability of a self-consumption residential system located in Madrid is assessed. The proposed solution comprises two kinds of heat stores: a low-or medium-grade heat store for domestic hot water and space heating, and a high-grade heat store for combined heat and power generation. Two cases are considered where the energy that is wasted during the conversion of heat into electricity is employed to satisfy either the heating demand, or both heating and cooling demands by using a thermally-driven heat pump. We compare these solutions against a reference case that relies on the consumption of grid electricity and natural gas and uses an electrically-driven heat pump for cooling. The results show that, under relatively favourable conditions, the proposed solution that uses an electrically-driven heat pump could provide electricity savings in the range of $70-90 \%$ with a payback period of 12 - 15 years, plus an additional $10-20 \%$ reduction in the fuel consumption. Shorter payback periods, lower than 10 years, could be attained by using a highly efficient thermally driven heat pump, at the expense of increasing the fuel consumption and the greenhouse gas emissions. Hybridising this solution with solar thermal heating could enable significant savings on the global emissions, whilst keeping a high amount of savings in grid electricity $(>70 \%)$ and a reasonably short payback period $(<12$ years).
\end{abstract}

\section{Introduction}

The energy consumption in buildings represents around $40 \%$ of the world energy consumption and one-third of global $\mathrm{CO}_{2}$ emissions [1]. Thus, during the last decade a number of technological solutions have been proposed targeting the improvement of the energy efficiency and the reduction of the $\mathrm{CO}_{2}$ emissions associated to energy consumption in the building sector. Among them, the so-called combined cooling, heating and power (CCHP), or trigeneration systems [2-6] are of especial interest, as they are intended to reduce the emissions associated to the three main kinds of energy demands in a building: electricity, heating and cooling. A typical CCHP system comprises a power generation unit (PGU), e.g. a microturbine, and a thermallydriven heat pump (THP) [7], e.g. an absorption chiller. The PGU is typically powered by natural gas and produces electricity and heat as by-product. This heat can be directly used for heating in winter or transferred to a THP for cooling in summer. Compared with the solution based on large centralized power plants and local air-conditioning systems, distributed CCHP provides a significant improvement of fuel utilization, in the range of 70 to $90 \%$ with respect to $30-45 \%$ of 
centralized power plants [2]. Further reduction of the emissions is possible by fully or partially replacing natural gas by solar thermal heating [8]. Most of the studies consider organic Rankine cycles (ORC) $[9,10]$ in this case, as they enable operation temperatures below $220^{\circ} \mathrm{C}$, meeting the requirements of non-concentrating solar collectors that could be used in residential and commercial environments. However, the low exergy content of such a low-grade heat results in very low PGU conversion efficiencies, typically below $10-15 \%$ [9,11,12], which precludes the achievement of a clear economic advantage.

In the last decade, the dramatic cost reductions of solar PV technology have triggered the interest on self-consumption of PV electricity in both commercial and residential buildings [13]. With an average growth rate of 51\% [14], new solar PV power additions in 2017 accounted up to $98 \mathrm{GW}$, out-stripping the $70 \mathrm{GW}$ of net fossil fuel generating capacity added the same year. Small-scale solar PV systems in distributed applications, mostly building integration, accounts for a significant share of these new PV additions ( $38 \%$ [15]). Only in China, distributed capacity additions in 2017 summed up to $19.4 \mathrm{GW}$, and new rooftop systems saw a three-fold increase relative to 2016 [14]. Solar PV installations are simple, reliable, and do not require high maintenance. Thus, they are very appealing to produce electricity in small distributed applications. In the residential context, many solutions have been proposed to integrate solar PV systems with CCHP systems, including the hybridization of solar PV with gas-powered CCHP [16-19], the use of hybrid PV/thermal (PVT) solar collectors, using both non-concentrating [10,20-23] and concentrating technologies [24], the integration of PV systems with electrically-driven heat pumps (EHP) [25-27], as well as the direct use of PV electricity for heat production [28].

In all these cases, the self-consumption of PV electricity is limited due to the lack of synchronization between solar irradiance and local consumption. For systems where PV electricity is used exclusively to satisfy the electric power demand, self-consumption ratio (defined here as the fraction of the PV generated electricity that is used to supply the loads) is usually limited to $25-30 \%$ [29]. Self-consumption can be increased in systems where solar PV electricity is also used to provide heating and cooling $[13,25,30,31]$. However, in this case, the attainable self-consumption ratio strongly depends on the climate conditions and the building standardized heating load. For instance, in old building standards located in Stuttgart (Germany), the combination of a heat pump and a hot water storage enable self-consumption increments of $\sim 35 \%$ [25]. However, for next generation zero-energy buildings the same solution provides self-consumption potential increments of only $\sim 10 \%$, as energy demand of appliances dominates compared to the electrical energy demand to drive the heat pump [25].

To increase the self-consumption levels, solutions must integrate a system that stores the excess of PV electricity, such as electrochemical batteries $[16-18,32]$. However, current prices for stationary residential battery storage are prohibitive, exceeding 1000 US $\$_{2015}$ per $\mathrm{kWh}$ of electricity storage capacity [33]. Even in the case of reaching global cumulative storage capacities of $1000 \mathrm{GWh}$ (from a current cumulative capacity of $\sim 1 \mathrm{GWh}$ ), empirical learning curves project that the future cost of stationary residential electricity storage, regardless of the technology type, will be in the range of $\sim 340 \$_{2015} / \mathrm{kWh}_{\mathrm{el}}$ [33]. Additionally, in most CCHP systems lifetime ( $>20$ years), the batteries require replacement (4-15 years) and this can have a significant impact on the lifetime cost of the full installation [16]. Consequently, when looking at the profitability of the CCHP solution, the high capital cost of batteries results in optimal systems with a relatively small storage capacity, consequently providing small self-consumption improvements in the range of $13-24 \%$ [13]. For this reason, finding low-cost alternatives for electricity storage in the residential sector is an important field of research today [34,35].

Although it might sound counterintuitive, among the many possible energy storage options, those that are particularly interesting for CCHP applications are those with low round-trip (electric-to-electric) efficiency, as they may deliver part of the stored energy in a form of heat. Some examples are compressed air [36] or hydrogen storage combined with fuel cells [37]. In these cases, the comparatively low round-trip efficiency can be compensated by the (eventual) lower cost of the technology and the profitable use of the exhaust heat. In this regard, a potentially low-cost alternative for electricity storage that has not received much attention is the power-to-heat-to-power storage (PHPS) concept. PHPS involves the conversion of electricity into heat, which is then stored and later converted back to electricity on demand. The dramatic cost reduction of solar PV electricity along with the potentially lower capital costs of PHPS might result in a profitable PV + PHPS solution in the context of CCHP applications, where the low-grade heat produced during the heat-to-power conversion process may be used for satisfying both heating and cooling demands. Today, the use of thermal storage for power generation is virtually limited to concentrated solar power (CSP) plants, where the store temperature rarely surpasses $\sim 500{ }^{\circ} \mathrm{C}$ [38]. On the contrary PHPS systems could theoretically reach ultra-high temperatures $\left(>1000^{\circ} \mathrm{C}\right)$, subsequently enabling very high heat-to-power $(\mathrm{H} 2 \mathrm{P})$ conversion efficiencies of $\sim 40 \%$ or beyond. This is around 3-4 times greater than that of lowtemperature solar thermal ORC systems discussed above $[9,11,12]$. A hypothetical system comprising a $40 \%$ efficient solar thermal collector and a $10 \%$ efficient ORC $[39,9]$ would produce an overall solar-toelectric conversion efficiency of $4 \%$, which is half the efficiency than that of a PHPS system comprising 20\% efficient solar PV modules and $40 \%$ efficient PGU. Besides, the use of high grade heat store would potentially enable much more efficient THP cooling, as well as higher stored energy densities $[40,41]$, which is a remarkable advantage in space constrained residential applications.

Recent studies have established a few conceptual PHPS embodiments, which differentiate in the way that heat is produced, stored, and converted back into electricity. A particularly promising concept is pumped heat electricity storage (PHES), in which a high temperature heat pump cycle transforms electricity into heat, which is stored inside two large regenerators, and a thermal engine cycle transforms the stored heat back into electricity [42-44]. PHES has a high theoretical round-trip efficiency (RTE) in the range of $40-70 \%$, depending on the operational temperature range [43]. Predominately conceived for large grid-electricity storage applications, the potential viability of PHES in the residential sector has not been assessed yet. Other conceptually simpler approaches consider the use of ultra-high temperature $\left(>1000^{\circ} \mathrm{C}\right.$ ) joule heating for sensible- $[45]$ and latent- $[40]$ heat storage combined with a thermophotovoltaic (TPV) power generation. Despite having lower RTE potential (less than $\sim 40 \%$ ), these designs might bring some advantages, as the modularity and the lack of moving parts. Solutions based on the use of high temperature heat pumps have been also recently proposed to mitigate the high thermal losses that could be eventually derived from operating at ultra-high temperatures; theoretically enabling an increment of the round-trip conversion efficiency up to $\sim 50 \%[46,47]$.

Regardless of the particular system implementation, it is still unclear under what circumstances a PHPS system could be profitable. In $[45,48]$ the minimum tolerable RTE of an energy storage system used for grid-electricity storage is estimated at $36 \%$ for the case of Pennsylvania-New-Jersey-Maryland grid in 2017. However, this study assumes that the electricity is purchased from the grid, and therefore, the minimum RTE is entirely determined by the ratio between on-peak and off-peak electrical prices in a very specific case. Besides, the exhaust heat produced by the PGU is not used, which is detrimental for the profitability of a PHPS solution. In this study we assess the integration of a PHPS system in a CCHP solution for the self-consumption of solar PV electricity in the residential environment. To the best of our knowledge, no comprehensive techno-economical assessment of PV generation coupled with a PHPS system has been evaluated so far. Thus, 


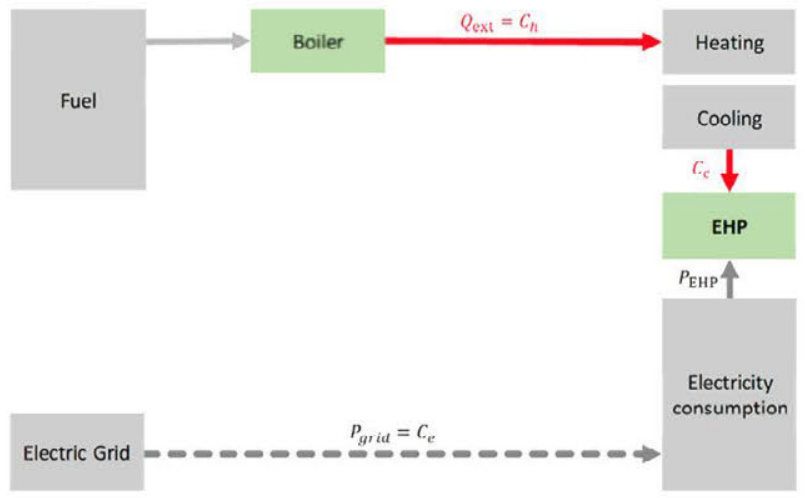

(a) REF

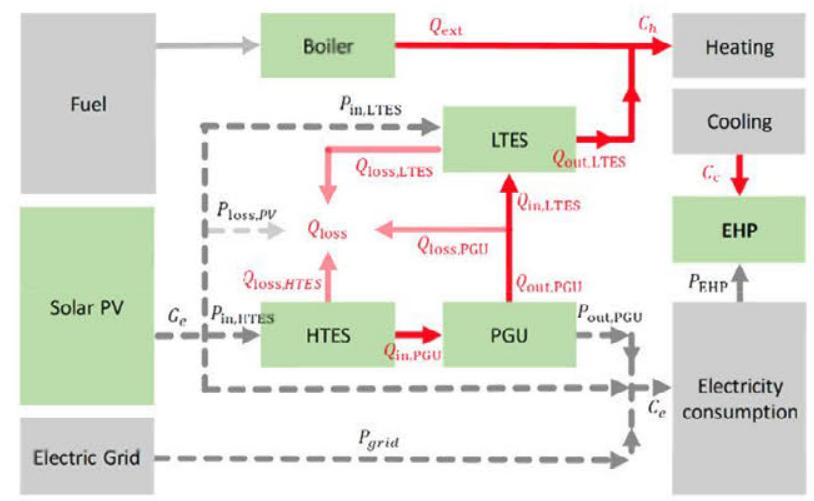

(b) PHPS-E

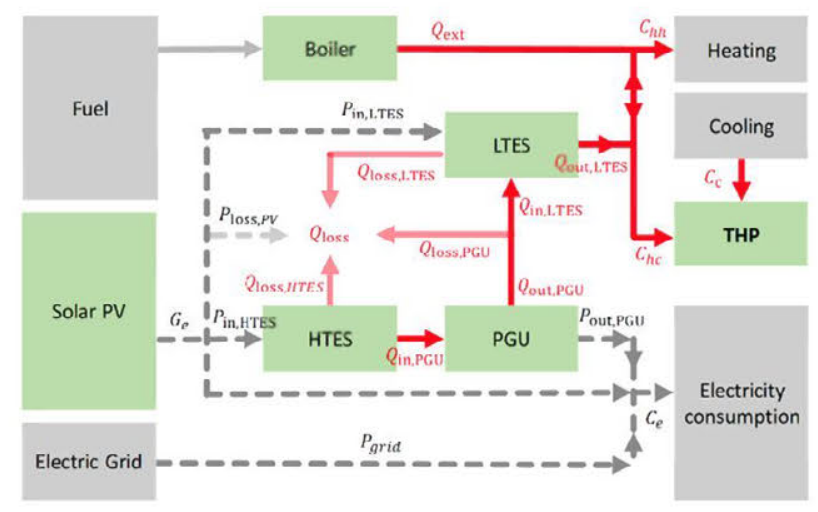

(c) PHPS-T

Fig. 1. Illustration of the electrical (grey dashed lines) and thermal (red solid lines) energy flows in the system configurations analysed in this study: (a) reference case comprising a boiler for heating and an electrically driven heat pump (EHP) for cooling, (b) PHPS-E configuration comprising an EHP for cooling, a solar PV system, a high- and low-grade thermal stores (HTES and LTES, respectively), and a power generation unit (PGU), (c) PHPS-T configuration similar to the PHPS-E but using a thermally-driven heat pump (THP) instead of an EHP. Notice that in each case, the variables take different values (e.g. the electricity consumption $\mathrm{C}_{\mathrm{e}}$ is lower in the PHPS-T system than in the other two cases). The same notation is used to avoid an excessively complicated notation.

we will answer some of the most fundamental questions regarding the profitability of this solution, such as the maximum cost, the minimum PGU conversion efficiency, or the maximum heat insulation losses that are tolerable in order to provide reasonably low payback periods and significant energy savings.

\section{System model and methodology}

Fig. 1 shows the three kinds of system configurations that are analysed in this work. The reference case (Fig. 1a) comprises a conventional boiler (for heating) and an EHP (for cooling). In this case, all the energy consumption, either electricity $\left(C_{e}\right)$ or heat $\left(C_{h}\right)$, is obtained from the retail markets. This reference case will be used to evaluate the relative improvements of the proposed solutions incorporating a PHPS system. Fig. 1b illustrates a PHPS configuration comprising a solar PV system, high-grade thermal energy store (HTES), a PGU, a low- or midgrade thermal energy store (LTES), and an EHP. Grid electricity and fuel are used as backups to ensure reliability of energy supply. In what follows, this configuration will be named PHPS-E. Fig. 1c illustrates a very similar configuration but using a thermally-driven heat pump (THP), instead of an EHP. This configuration will be named PHPS-T. In both configurations the PV electricity $\left(G_{e}\right)$ is either (i) used directly to satisfy the electric demand, (ii) stored as high-grade heat in the HTES $\left(P_{i n, H T E S}\right)$, (iii) stored as low-grade heat in the LTES $\left(P_{i n, L T E S}\right)$, or (iv) lost $\left(P_{l o s s, P V}\right)$ if there is no electricity consumption and both HTES and LTES stores are at their maximum capacities $\left(E_{\text {IITES, } \max }\right.$ and $E_{\text {LTLS, } \max }$, respectively). The possibility of selling the excesses of PV electricity to the grid is not considered in this study. The high-grade heat stored in the HTES can be supplied on demand to the PGU $\left(Q_{i n, P G U}\right)$ to produce electricity with a conversion efficiency $\eta_{P G U}\left(P_{\text {out }, P G U}=\eta_{P G U} Q_{i n, P G U}\right)$. During this process, the produced low-grade exhaust heat $Q_{o u t, P G U}=\left(1-\eta_{P G U}\right) Q_{i n, P G U}$ can be either stored in the LTES $\left(Q_{\text {in.LTES }}\right)$, or lost $\left(Q_{\text {loss.PGU }}\right)$ if the LTES is at maximum capacity. Additional losses take place due to the non-ideal thermal insulation of the LTES $\left(Q_{\text {loss }, L T E S}\right)$ and the HTES ( $\left.Q_{\text {loss }, H T E S}\right)$. All these kinds of losses $\left(Q_{\text {loss }}=Q_{\text {loss }, \text { ITES }}+Q_{\text {loss }, L T E S}+Q_{\text {loss }, P G U}+P_{P V, \text { loss }}\right)$ contribute to reduce the self-consumption ratio, defined in this work as $S C=1-\sum_{t=1}^{8760 T} Q_{\text {loss }}(t) / \sum_{t=1}^{8760 T} G_{e}(t)$, being $8760 \times T$ the total number of hours during the entire system lifetime $T$ (in years).

The cooling power $\left(C_{c}\right)$ is satisfied by either an EHP (case PHPS-E, Fig. 1b) or a THP (case PHPS-T, Fig. 1c). The former case implies an extra consumption of electricity $\left(P_{E H P}=C_{c} / C O P_{E H P}\right)$, whereas the latter implies an extra consumption of heat $\left(C_{h c}=C_{c} / C O P_{T H P}\right)$. The coefficient of performance (COP) of each device indicates the ratio between the useful cooling provided to the input energy, either heat (THP) or electricity (EHP). The low-grade heat in the LTES can be used either to satisfy the space heating and domestic hot water demands $\left(C_{h}=C_{h h}\right)$ in the PHPS-E configuration (Fig. 1b) or both heating and cooling demands $\left(C_{h}=C_{h h}+C_{h c}\right)$ in the PHPS-T configuration (Fig. 1c). In both cases, additional heating from the external boiler $\left(Q_{e x t}\right)$ might be necessary to ensure supply reliability. Notice that in the PHPS-T configuration (Fig. 1c) an additional heat coming from the boiler may be needed for satisfying the cooling demand. Hybrid absorption-compression heat pumps [49] enabling both heat and electricity inputs might be interesting in this application, but they are not considered in this study for the sake of simplicity.

In this study we use simplified models for each device of the PHPS system. The detailed model equations are shown in Fig. 2, which also illustrates the energy management algorithm. At every time step ( $\Delta t=1$ hour), the energy rates (in $\mathrm{kW}_{\mathrm{el}}$ and $\mathrm{kW}_{\mathrm{th}}$ ) shown in Fig. 1, and the stored energy (in $\mathrm{kWh}_{\mathrm{th}}$ ) in the HTES and LTES ( $E_{\text {HTES }}$ and $E_{\text {LTES }}$, respectively) are calculated following the procedure illustrated in Fig. 2. This algorithm first evaluates whether there is an excess or defect of generated PV electricity, i.e. whether the net consumed electrical power $P_{n e t}=C_{c}-G_{c}$ is negative or positive, respectively. If demand exceeds the PV generation $\left(C_{e}<G_{e}\right)$, all the PV electricity is directly used to satisfy that demand. The additional electricity $\left(P_{n e t}\right)$ is supplied by either the PGU, if the HTES has enough stored heat ( $E_{H T E S}>P_{n e t} \Delta t / \eta_{P G U}$ ), or by the electrical grid, in the opposite case. If the electrical power demand is higher than the maximum power capacity of the PGU $\left(P_{\text {net }}>P_{\max . P G U}\right)$, both the PGU and the electrical grid contribute to satisfy such demand. The low-grade heat produced during 


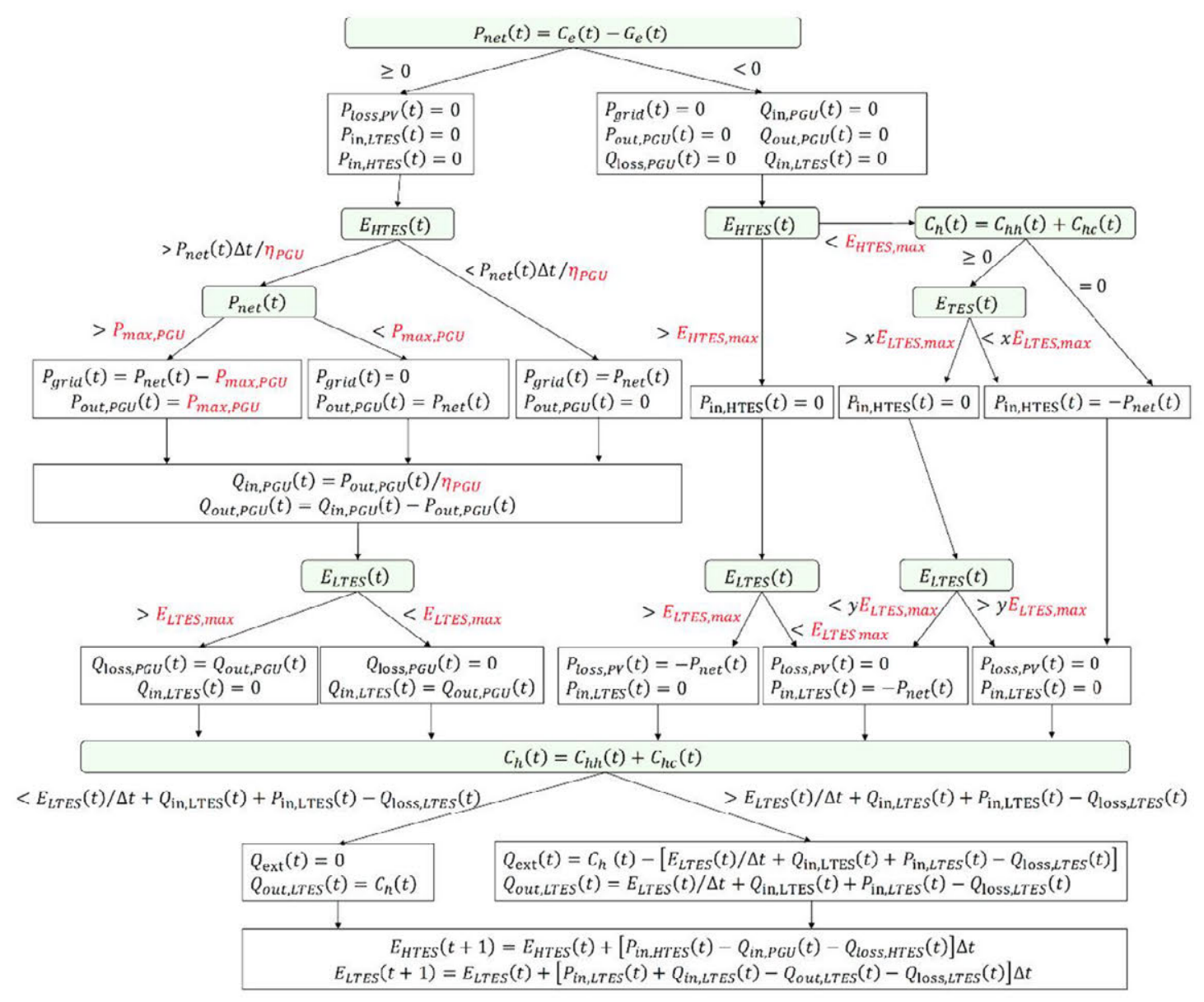

Fig. 2. Energy management algorithm and system model equations.

the operation of the PGU ( $\left.Q_{\text {out } . P G U}\right)$ may be stored in the LTES, if this is not already at its maximum capacity. In the case the PV generation exceeds the consumption of electricity $\left(G_{e}>C_{e}\right)$, such excess may be stored as high-grade heat in the HTES or as low-grade heat in the LTES. In principle, the system will prioritize the charge of the HTES, as it stores a higher-grade heat that can be later converted into electricity by the PGU. There is only one scenario where this excess of PV electricity is stored in the LTES instead of HTES. This is the case that there is heat consumption $\left(C_{h}=C_{h h}+C_{h c}>0\right)$, the HTES charge is high $\left(E_{\text {HTES }}>x E_{\text {HTES.max }}\right)$, and the LTES charge is low $\left(E_{\text {LTES }}<y E_{\text {LTES.max }}\right)$. In this study we have fixed $x=0.99$ and $y=0.1$, which means that this situation is very improbable, and the vast majority of the excesses of PV electricity is stored in the HTES rather than in the LTES. The optimization of the values of the parameters $x$ and $y$ is out of the scope of this work. In the case that both LTES and HTES are at their maximum capacities, the PV electricity is inevitably lost, contributing to the increase of the total energy losses of the system $\left(Q_{\text {loss }}\right)$. Finally, the total heat consumption $\left(C_{h}=C_{h h}+C_{h c}\right)$ is satisfied either by the LTES, the boiler, or both combined, depending on whether the amount of stored heat in the LTES is enough to fully satisfy the heat demand. The amount of heat stored in the HTES and LTES is updated at every time step by evaluating the corresponding energy balance equations, as shown at the bottom of Fig. 2.

The model described above assumes no exergy degradation of stored heat in both HTES and LTES. A non-degraded heat flowing out of the high-grade HTES enables assuming a constant PGU conversion efficiency during the full discharge cycle. This assumption is reasonable especially for thermal stores based on latent heat, where exergy losses are minimum. The energy losses in the LTES are approximated using the standard EN 12977-3 for hot water stores, according to which the heat loss rate in $\mathrm{W} / \mathrm{K}$ is $U A_{\text {LTES }}=a_{\text {LTES }} \sqrt{V_{\text {LTES }}}$, being $V_{\text {LTES }}$ the water volume in litres, and $a_{\text {LTES }}$ a constant that usually takes a value of $\sim 0.1$ for good insulated hot water stores. The overall heat losses (in $\mathrm{W}$ ) are approximated by $Q_{\text {loss }, L T E S}=a_{\text {LTES }} \sqrt{V_{\text {LTES }}} \Delta T_{\text {LTES }}$, being $\Delta T_{\text {LTES }}$ the mean difference between LTES and ambient temperatures (assumed $\Delta T_{\text {LTES }}=70^{\circ} \mathrm{C}$ for the PHPS-E system and $\Delta T_{\text {LTES }}=130{ }^{\circ} \mathrm{C}$ for the PHPS$\mathrm{T}$ one, as the later requires higher temperature to operate a highly efficient thermally driven heat pump). The heat losses in the HTES are calculated using a similar approach, so that $Q_{\text {loss }, H T E S}=a_{\text {HTES }} \sqrt{V_{\text {HTES }}} \Delta T_{\text {HTES }}$, being $a_{\text {HTES }}$ an unknown parameter that should be eventually determined for high temperature heat stores. To relate the volume ( $V_{\text {HTES }}$ and $V_{\text {LTES }}$ ) with the storage maximum capacity $\left(E_{H T E S, \text { max }}\right.$ and $\left.E_{L T E S, \text { max }}\right)$ we assume an energy storage density of $0.08 \mathrm{kWh}_{\mathrm{th}} / 1$ for the LTES, corresponding to that of a hot water store, while for the HTES, the energy density strongly depends on the storage media and its operational temperature. In this study we assume a latent heat store with an energy density that depends on the operational temperature according to the following equation: $E_{d, T E S}=6.74 \times 10^{-7}\left(T_{T E S}\right)^{2}-1.72 \times 10^{-4} T_{T E S}+0.140$ that has been obtained from fitting the latent heat of fusion of a few pure metals with different melting points in the range of $230-2070{ }^{\circ} \mathrm{C}(\mathrm{Sn}, \mathrm{Zn}, \mathrm{Al}, \mathrm{Si}$ and B) $[40]$. This equation captures the fact that higher temperatures enable higher stored energy densities. For instance, a $20 \mathrm{kWh}_{\mathrm{th}}$ HTES operating at $1414^{\circ} \mathrm{C}$ (which will be the case if silicon is used as phase-change material) would have an energy density of $1.24 \mathrm{kWh}_{\mathrm{th}} / \mathrm{l}$ (silicon latent heat). Assuming an optimistic value for $a_{\text {HTES }}$ of 0.1 , such HTES system would lose about $2.8 \%$ of its maximum stored energy in one hour. As a reference, a hot-water store of the same capacity and with $a_{\text {LTES }}=0.1$ would lose only $0.24 \%$ per hour. For a HTES at $800^{\circ} \mathrm{C}$, heat losses would be only very slightly reduced to $2.7 \%$ (assuming the same value 
of $\left.a_{\text {HTES }}\right)$. This is because the lower temperature also brings a lower energy density, counteracting to keep a similar amount of heat losses. The evident way to reduce the losses is the use of advanced thermal insulation designs with a very small $a_{\text {HTES }}$ value. Possible options include the use of vacuum insulation or other advance concepts, such as the use of heat pumps [46]. Whether such low $a_{H T E S}$ values are attainable by practical thermal insulation systems is out of the scope of this work. Our aim is to provide its bounds in order to reach profitability in a PHPS application. An additional possibility to reduce heat losses in the HTES is to use eutectic alloys, instead of pure elements, with enhanced latent heats at lower melting temperatures, such as $\mathrm{Al}$ $12 \mathrm{Si}\left(549 \mathrm{kWh} / \mathrm{m}^{3}\right.$ at $\left.577^{\circ} \mathrm{C}\right)$ [50] or Fe-26.3Si-9.3B $\left(\sim 1240 \mathrm{kWh} / \mathrm{m}^{3}\right.$ at $\sim 1200^{\circ} \mathrm{C}$ ) [41].

Time-dependent profiles of heating (space and hot water), cooling, and electricity consumptions $\left(C_{h h}\right.$ and $\left.C_{c}, C_{e}\right)$ are obtained by the Energy Plus software [51] for a detached household with two floors with an area of $60 \mathrm{~m}^{2}$ each, $30 \%$ of openings (glazing), the U-value of the façade is $0.26 \mathrm{~W} /\left(\mathrm{m}^{2} \mathrm{~K}\right)$ and the $\mathrm{U}$-value of the roof is $0.18 \mathrm{~W} /\left(\mathrm{m}^{2} \mathrm{~K}\right)$. These $\mathrm{U}$ values match with the guidelines provided in the Spanish Building Code [52], which in turn are also in agreement with the corresponding guidelines of most of the European countries [53,54]. For the energy simulations, typical occupancy profiles of a 4-inhabitant house ( 2 adults and 2 children) are considered. The simulations differentiate between working and non-working days, and provide loads, schedules for lighting and home appliances, as well as for occupancy, and the air renovations in the different months. The primary and secondary setpoints for air conditioning in summer (i.e. from June to September) are $25^{\circ} \mathrm{C}$ and $27^{\circ} \mathrm{C}$, respectively, while primary and secondary temperature set-points for space heating (i.e. from January to October) are $20^{\circ} \mathrm{C}$ and $17^{\circ} \mathrm{C}$. DHW inlet/delivery temperature is $15 / 60^{\circ} \mathrm{C}$ and the normalized lighting power density in $\mathrm{W} / \mathrm{m}^{2}-1001 \mathrm{x}$ is 5 . The Energy Plus software calculates the energy consumption (for heating, cooling and DHW) of a given household for a user-defined HVAC and DHW systems, thus resultant energy consumption will depend on the conversion efficiency of the selected systems. In the particular case of the electricity, electricity demand will be equal to electricity consumption if no losses are considered. Therefore, in order to obtain energy demand profiles which will be later inputs in our system model, conversion efficiency of the HVAC and DHW systems is set to 1. Energy simulations of the reference building consider 1-hour step weather data from Energy Plus ${ }^{\mathrm{TM}}$ database, which includes: direct and diffuse solar irradiance, solar height and azimuth, atmospheric pressure, ambient temperature and wind direction and velocity. Finally, from the energy simulations, hourly global energy demand of the reference building over a year is calculated. Thus, 1-hour step data of electricity for lighting and other appliances, cooling, domestic hot water (DHW) and space heating demands is obtained. The hourly PV electrical power generation per $\mathrm{kW}$ of installed PV capacity ( $G_{e}^{*}$, in equivalent hours) in Madrid is calculated by means of the PVsyst software [55]; and considering the same weather data from Energy Plus ${ }^{\mathrm{TM}}$ database for coherence with the timedependent energy consumption profiles. For this calculation monocrystalline silicon PV modules of $318 \mathrm{Wp}$ from the manufacturer SunPower and a Sunny Boy series inverter of the manufacturer SMA have been considered. PV modules are orientated to the South and their tilt angle is $34^{\circ}$, which is the optimum value that maximises the annual PV generation in Madrid. For the comprehensive system model, energy output after the inverter is considered. The total PV electricity generated during one hour $\left(G_{e}\right.$, in $\left.\mathrm{kWh}\right)$ is estimated from these simulations as $G_{e}=G_{c}^{*} P_{n o m, P V}$, being $P_{n o m, P V}$ the nominal PV installed power (in $\mathrm{kW}$ ).

Fig. 3a shows an example of the resultant electrical (top) and thermal (bottom) energy rates along with the amount of energy stored in the HTES (top, solid line) and LTES (bottom, solid line) for a system with $\quad \eta_{P G U}=30 \%, P_{\text {nom }, P V}=10.6 \quad \mathrm{~kW}_{\mathrm{el}}, \quad P_{\max , P G U}=1.35 \quad \mathrm{~kW}_{\mathrm{el}}$, and $E_{\max , \text { HTES }}=33.7 \mathrm{kWh}_{\mathrm{th}}$. As it will be seen in the discussion section, the sizing of the three key elements of this system, i.e. the PV, HTES and PGU, has been optimized to minimize the cost of the consumed electricity all through the lifetime of the installation. The proper selection of the merit function that must be minimized is of extreme relevance, as different merit functions provide completely different optimum solutions. For instance, a key performance indicator of the system could be its levelized cost of total (consumed) energy or LCOE, which is defined in this work as:

$$
L C O E=\frac{C A P E X+\sum_{i=1}^{T}\left[\frac{\text { OPEX }_{(i)}}{\left(1+\text { WACC }_{\text {nom }}\right)^{i}}\right]}{\sum_{i=1}^{T}\left[\frac{\sum_{t=1}^{8760}\left(C_{e}(t)+C_{h}(t)\right) \Delta t}{\left(1+\text { WACC }_{\text {real }}\right)^{i}}\right]}
$$

where CAPEX is the total capital expenditure (in $€$ ), $t$ is the time variable (in years), $T$ is the total lifetime of the installation (in years), OPEX $(t)$ are the total operational expenditures in year $t$ (in $€$ ), and $\sum_{t=1}^{8760}\left(C_{e}(t)+C_{h}(t)\right) \Delta t$ is the total energy consumption (in kWh) during a year, evaluated at time intervals of $\Delta t=1$ hour. $W A C C_{\text {nom }}$ and $W A C C_{\text {real }}$ are the nominal and real weighted average cost of capital, respectively, and are mutually related throughWACC $C_{\text {real }}=\left(1+W A C C_{n o m}\right) /(1+$ Infl $)-1$, being Infl the annual inflation rate. The CAPEX of the solution is the addition of the individual CAPEX of each element (PV, HTES, LTES, PGU, Boiler, and THP or EHP), each of which are assumed proportional to the element's nominal capacity. For instance, the CAPEX of the PV system is estimated as $C A P E X_{P V}=C A P E X_{P V}^{*} P_{n o m, P V}$, being $C A P E X_{P V}^{*}$ the capital expenditure per $\mathrm{kW}$ of a $\mathrm{PV}$ installation.

A key difference of Eq. (1) with respect to conventional definitions of LCOE is that in the denominator we put the total energy consumption, rather than the electricity generated by the PV system. Thus, the LCOE defined in Eq. (1) refers to the cost of the total amount of energy that is consumed (heat plus electricity), including the cost of the electricity and the fuel that are purchased from the grid. The OPEX $\left(t^{\prime}\right)$ is calculated as

$$
\begin{aligned}
& \text { OPEX }\left(t^{\prime}\right) \\
& =\left(1+\operatorname{Infl}_{\text {cl }}\right)^{i}\left\{\text { OPEX } X_{\text {elec }, \text { fix }}^{*} \max \left[P_{\text {grid }}(t)\right]+O P E X_{\text {elec,var }}^{*} \sum_{t=1}^{8760} P_{\text {grid }}\right. \\
& \quad(t) \Delta t\}+\left(1+\operatorname{Infl}_{\text {fuel }}\right)^{t}\left\{\text { OPEX } X_{\text {fuel, fix }}+\text { OPEX fuel,var } \sum_{t=1}^{8760} Q_{\text {ext }}(t) \Delta t\right\}
\end{aligned}
$$

where $O P E X_{\text {clec } f i x}^{*}$ is the fixed annual cost per installed electric-grid power capacity in current money, and $\max \left[P_{\text {grid }}(t)\right]$ is the maximum peak-power demanded to the electrical grid, assumed here to be equal to the maximum grid power capacity. This is an important assumption, as the incorporation of storage in the system enables a significant reduction of $\max \left[P_{\text {grid }}(t)\right]$, subsequently providing a noticeable reduction in the fixed costs of external electric power supply. OPEX $X_{f u c l, f i x}$ is the annual fixed cost of fuel, while $O P E X_{\text {elec,var }}^{*}$ and $O P E X_{\text {fuel,var }}^{*}$ are the annual costs of externally-purchased electricity and heat (in $€ / \mathrm{kWh}_{\mathrm{el}}$ and $€ / \mathrm{kWh}_{\mathrm{th}}$ ) expressed in current money. Eq. (2) implicitly assumes that electricity and fuel prices increase with constant annual energy inflation rates $I n f l_{l l}$ and $I n f l_{f u e l}$, respectively (which are not necessarily equal to the overall economy inflation rate $(n f l)$, and that all years are identical in terms of energy generation and consumption. Other kinds of operational expenditures, such as taxes and the maintenance costs, are neglected.

Preliminary attempts to minimize the total LCOE, as defined in Eq. (1), resulted in "optimal" solutions tending to maximize the amount of PV electricity dedicated to produce heat. This subsequently resulted in large PV, HTES and LTES systems. Despite the fact that this brings some economical savings after the entire lifetime of the installation, the very high CAPEX results in an intolerable increase of the discounted payback period. As a consequence, we opted for using the levelized cost of consumed electricity $\left(\mathrm{LCOE}_{\mathrm{el}}\right)$ as merit function, which is defined in this work as: 